\title{
Variação Lexical no Atlas Linguístico do Amapá
}

\author{
Lexical Variation in Atlas Linguistic Amapá \\ Celeste Maria da Rocha RIBEIRO* \\ Universidade Federal do Amapá (UNIFAP)
}

\begin{abstract}
RESUMO: Este artigo apresenta um recorte da variação semântico-lexical nos dados do Atlas Linguístico do Amapá (RAZKY; RIBEIRO; SANCHES, 2017). A análise dos dados segue os pressupostos teórico-metodológicos da Dialetologia e da Geossocioinguística. A amostra é composta de dados orais de 40 falantes, os quais foram submetidos à aplicação do questionário semântico-lexical que contém 202 questões, distribuídas em 14 campos semânticos. Este estudo focaliza as questões que evidenciaram produtividade no tocante à realização de variantes relacionadas ao campo semântico "convívio e comportamento social". Os resultados, nesse estudo, destacados em quadros e cartas refletem o perfil da variação semântico-lexical, deste campo, no falar amapaense, refletindo a diversidade do português brasileiro usado no Amapá.
\end{abstract}

PALAVRAS-CHAVE: variação lexical. atlas linguístico. geossociolinguística.

\begin{abstract}
This article presents a cut-out of the semantic-lexical variation in the data from the Linguistic Atlas of Amapá (RAZKY; RIBEIRO; SANCHES, 2017). Data analysis follows the theoretical and methodological assumptions of Dialectology and Geosocioinguistics. The sample is composed of oral data from 40 speakers, who were submitted to the application of the semantic-lexical questionnaire containing 202 questions, distributed in 14 semantic fields. This study focuses on the issues that showed productivity in relation to the realization of variants related to the semantic field "socializing and social behavior". The results in this study, highlighted in charts and letters, reflect the profile of the semantic-lexical variation of this field in Amapá speaking, reflecting the diversity of Brazilian Portuguese used in Amapá.
\end{abstract}

KEYWORDS: lexical variation; linguistic atlas; geossociolinguistics.

\footnotetext{
" Doutora em Linguística; Professora Adjunta do Departamento de Letras, Arte e Jornalismo da Universidade Federal do Amapá, Campus Marco Zero, Macapá/AP. e-mail: celribeiro042002@gmail.com.
}

Revista Moara, n. 54, ago-dez 2019 ISSN: 0104-0944 


\section{Introdução}

O presente estudo consiste em divulgar o resultado do levantamento realizado nos dados do Atlas Linguístico do Amapá - ALAP, a fim de identificar as variantes diatópicas, referentes aos itens lexicais mais produtivos no campo semântico "convívio e comportamento social", o qual está inserido no questionário semântico-lexical do Atlas Linguístico do Brasil - ALiB (COMITÊ NACIONAL DO PROJETO ALIB, 2001) e que também fora aplicado na coleta de dados do ALAP. Vale dizer que a diversidade linguística, nas últimas décadas, vem sendo estudada de forma muito intensa por todo o país.

Os projetos de atlas linguísticos concluídos, como o ALAP, ou em andamento, como o Atlas linguístico do Pará - ALIPA - representam ganhos significativos para a descrição, propagação e maior conhecimento do Português Brasileiro, uma vez que eles refletem, na atualidade, uma das principais fontes de registro da diversidade linguística no país. Convém destacar que a ampliação da descrição dessa diversidade deve-se muito aos aparatos teórico-metodológicos da geolinguística atual, com instrumentos que dão suporte à realização de uma pesquisa de campo eficiente, ao tratamento dos dados e à análise dos resultados de forma consistente, adequada e confiável.

Desse modo, a contribuição trazida por este estudo vem somar-se às demais realizadas pela geolinguística moderna, por meio da explicitação e análise de 05 itens lexicais mapeados no ALAP e que também demonstraram produtividade em outras cidades da Região Norte do país, conforme Aragão (2009). Convém destacar que nesse trabalho a referida autora analisa 04 itens lexicais do Questionário Semântico Lexical do Atlas Linguístico do Brasil, pertencentes também ao campo semântico "convívio e comportamento social".

Conforme a pesquisadora, os "resultados vêm confirmar o que já vem sendo analisado por diversos trabalhos, de autores nortistas, sobre o léxico regional-popular". Para a análise, foram selecionados alguns itens lexicais, extraídos dos inquéritos experimentais, do Projeto Atlas Linguístico do Brasil, realizados nos estados do Amazonas, Pará, Amapá, Roraima, Acre e Rondônia. O objetivo da seleção e análise das cartas lexicais que evidenciam os itens "pessoa sovina", "marido enganado", "prostituta" e "bêbado" é verificar se tais variantes diatópicas "demarcam a Região 
Norte, distinguindo-a das demais regiões do país". Desse modo, tomamos por base esse estudo de Aragão (2009), que considera os registros das capitais dos estados da referida Região, haja vista a equivalência entre os itens lexicais estudados.

\section{Relação Sociolinguística, Dialetologia e Geolinguística}

Os estudos mais sólidos na área da Sociolinguística surgiram no Brasil somente em meados da década de 1970, com o propósito central de investigar a relação linguagem e fatores sociais responsáveis por distinguir e definir comunidades de fala, desconstruindo, assim, a ideia de homogeneidade linguística. Essa desconstrução que evidencia a diversidade linguística presente em uma sociedade tende a ser abordada em duas áreas de estudos: a Dialetologia que tem como escopo os dialetos, considerados como quaisquer variedades de uma língua e a Sociolinguística que estuda as diferentes formas de uso de uma língua no interior das comunidades de fala. No entanto, apesar de equivalentes e complementares, cada uma delas utiliza-se de um método de investigação particular. É nesse contexto que entra a geolinguística, tratada como um método da dialetologia na identificação espacial das variações linguísticas, situando-as socioculturalmente a cada um dos falantes considerados.

Ferreira e Cardoso (1994) informam que a Dialetologia surgiu como uma ciência nos fins do século XIX, interessando-se, inicialmente, pelos dialetos regionais, rurais e sua distribuição e intercomparação. Já Cardoso (2010), considera-a como um ramo dos estudos linguísticos que assume a tarefa de identificar, descrever e situar os diferentes usos de uma língua, considerando sua distribuição espacial, sociocultural e cronológica. Segundo Thun (2017) os trabalhos iniciais voltados à variação diatópica envolviam um número muito reduzido de fatores sociais e tinham como principal objetivo o registro areal dos chamados "dialetos de uma mesma língua" (Thun, 2017, p. 4).

No entanto, as mudanças relativas às expansões urbanas, os frequentes movimentos migratórios e o avanço das diferentes tecnologias possibilitando uma maior integração entre os povos de todo o planeta levam a chamada dialetologia tradicional a um processo de adaptação a esse novo panorama, dando início, assim, a um novo

período para os estudos dialetais, denominado Dialetologia Pluridimenisonal e 
Relacional (Thun, 1997). Essa Dialetologia enquanto disciplina geral da variação linguística considera tanto a dimensão diatópica, foco principal da dialetologia, quanto a dimensão social, escopo central da sociolinguística (Thun, 1997, p. 705).

Diante desse novo cenário nos estudos dialetológicos, Cardoso (2016, p. 13) define a Dialetologia como o "ramo da linguística que se ocupa da identificação e da descrição dos diferentes usos de uma determinada língua, considerando a distribuição diatópica, os aspectos sociais e a cronologia dos dados”. A Geografia Linguística, como método da Dialetologia, tem como principais objetivos: (a) realizar a descrição das variedades linguísticas em um determinado espaço geográfico; (b) qualificar as ocorrências consideradas pelo aspecto social; (c) analisar tais ocorrências a partir do período em que estão submetidas. Dessa forma, Cardoso (2010) destaca a importância da coleta de dados in loco e a escolha de variáveis adequadas ao objetivo pretendido no estudo, em que num plano mais voltado ao escopo da Dialetologia ou da Sociolinguística, o pesquisador irá observá-las, controlá-las, identificá-las e analisá-las fazendo uso do método geolinguístico e da cartografia dos dados - carta linguística ou mapa linguístico.

\section{Os Atlas Linguísticos}

Conforme Coseriu (1982, p. 84) "os mapas linguísticos ... revelam a conexão entre a história linguística e os fatores geográficos ou geopolíticos ...”. Destaca ainda que os mapas linguísticos refletem a difusão das inovações e sua relação com fronteiras geográficas e políticas. De forma geral a pesquisa que considera postulados da geolinguística tende a desenvolver-se por meio de três etapas:

a) coleta de material, tipo de pesquisa, questionários e rede de pontos;

b) registro do material em mapas;

c) estudo e interpretação do material dos mapas;

Assim, esse tipo de pesquisa e a produção de atlas contribuem significativamente para uma visão global da realidade linguística pelo pesquisador. Segundo Cardoso (2002) as cartas linguísticas permitem o registro de dados diatópicos e sociais; porém, 
vale lembrar que essa inserção de dados sociais na cartografia das variantes provém do advento da Geolinguística Pluridimensional.

No Brasil, a construção dos atlas linguísticos tem início com o Atlas Prévio dos Falares Baianos (Rossi, 1963) o qual constitui o marco de partida para a produção de outros, sobretudo a partir da década de 70 quando se juntam ao atlas de Rossi, novos atlas regionais sempre com o propósito de descrever e mapear as variantes linguísticas de Unidades Federativas do país. Mas, sem dúvida, que foi em 1996 com o lançamento do Projeto Atlas Linguístico do Brasil - Projeto ALiB, durante o Seminário "Caminhos e Perspectivas para a Geolinguística no Brasil", ocorrido na Universidade Federal da Bahia, que foi dado o grande impulso para a produção de atlas pelo Brasil. Lançados os primeiros volumes em 2014, o ALiB (CARDOSO et al., 2014) visa, principalmente, documentar e mapear a língua falada em seus diversos aspectos, abrangendo 250 localidades representativas das diferentes regiões, distribuídas por todo o país.

O ALiB trouxe grandes contribuições ao desenvolvimento de estudos de natureza sociolinguística e dialetológica, não só por descrever a realidade linguística brasileira, pautando-se nos pressupostos teórico-metodológicos de uma geolinguística moderna, como também impulsionar a produção de atlas linguísticos regionais no Brasil.

Desse modo, destacamos que um dos atlas regionais que surgiu nesse contexto foi o Atlas Linguístico do Amapá - ALAP - (RAZKY; RIBEIRO; SANCHES, 2017) que, visa, de maneira mais ampla, documentar e mapear a língua falada no estado, em dez localidades amapaenses, destacando aspectos fonético-fonológicos e semântico-lexicais.

O Atlas Linguístico do Amapá foi publicado em 2017, na Universidade Federal do Amapá, pelos professores Abdelhak Razky, Celeste Ribeiro e Romário Sanches. Esse atlas considerou a mesma metodologia empregada no ALiB, totalizando 40 informantes, distribuídos equitativamente em dois sexos, duas faixas de idade e todos de escolaridade fundamental incompleto. Abrange os 10 municípios de maior representatividade demográfica, cultural e socioeconômica do estado do Amapá, a saber: Macapá (capital), Santana, Mazagão, Porto Grande, Laranjal do Jari, Pedra Branca do Amapari, Tartarugalzinho, Amapá, Calçoene e Oiapoque. Ele apresenta 16 cartas fonéticas, 73 cartas lexicais e 30 cartas estratificadas em sexo e idade, por localidade. O ALAP segue os parâmetros metodológicos da Dialetologia e da Geolinguística pluridimensional, considerando os aspectos diatópico e o diastrático. 
Para a coleta de dados, utilizaram-se dois questionários: o fonético-fonológico (QFF) com 159 questões e o semântico-lexical (QSL) com 202 perguntas; esses questionários foram os mesmos utilizados na recolha de dados do ALiB.

As cartas do ALAP apresentam o título do atlas, o número da carta, o tipo de pergunta, os pontos pesquisados, o item linguístico selecionado e as ocorrências mais recorrentes em cada município investigado, as porcentagens de ocorrências desses itens, além da pergunta do questionário utilizada para o item observado. As cartas não possuem nenhum tipo de notas ou comentários e os dados expostos apontam somente aspectos quantitativos.

Assim, o estudo proposto tem por base a análise de um campo presente no questionário semântico-lexical, o qual se encontra evidenciado em 15 cartas lexicais, dentre as 73 no total, considerando a variação diatópica dos itens que apresentaram maior diversidade lexical nos dados do ALAP. Dessas 15 cartas, esse estudo destaca somente os itens do campo "convívio e comportamento social" que se mostraram mais produtivos no léxico amapaense, a saber: pessoa tagarela; pessoa sovina; marido enganado; prostituta e bêbado.

Dessa maneira, para essa análise foram selecionadas 05 cartas semântico-lexicais do ALAP que evidenciam os itens citados anteriormente e suas respectivas variantes. Para se chegar ao mapeamento da variação diatópica, realizou-se a contagem do número de variantes lexicais em cada uma das cartas lexicais do referido atlas; em seguida, foi selecionado cada item lexical e suas respectivas variantes, os quais são indicados por meio do quadro 1 e de suas respectivas cartas linguísticas, em que será possível a visualização dos dados investigados. Ressaltamos que a escolha do campo "convívio e comportamento social" ocorre pela frequente descrição e mapeamento das variantes que configuram entre os itens lexicais desse campo, em variedades do português brasileiro (Aragão, 2009; Razky \& Costa, 2014; Sanches \& Razky, 2015), o que determinou o interesse em identificar as variantes lexicais designativas para os itens "pessoa tagarela"; "pessoa sovina"; "marido enganado"; "prostituta" e "bêbado", no estado amapaense.

Revista Moara, n. 54, ago-dez 2019 ISSN: 0104-0944 


\section{As Variações Léxico-Semânticas no Amapá}

Antes de serem apontadas as variações supracitadas, julgamos importante definir léxico e semântica. Considerando Biderman (2001), temos no léxico

um vasto universo de limites imprecisos e indefinidos. Abrange todo o universo conceptual dessa língua. O sistema léxico é a somatória de toda a experiência acumulada de uma sociedade e do acervo de sua cultura através das idades. Os membros dessa sociedade funcionam como sujeitos agentes, no processo de perpetuação e reelaboração contínua do Léxico da sua língua (BIDERMAN, 2001, p. 179).

O campo que envolve a semântica refere-se, de modo geral, às concepções que se relacionam ao sentido e ao significado. Pottier (1987) define semântica como "o conjunto dos traços semânticos pertinentes ou ainda, as significações lexicais e gramaticais”. Biderman (2001) acrescenta ainda que o elemento semântico se organiza em dois campos distintos: o indivíduo e o meio social. O léxico teria suas bases de origem na relação estabelecida entre esses campos.

Aragão (2009) destaca que "para se apreender, compreender, descrever e explicar a "visão de mundo" de um grupo sócio-linguístico-cultural, o objeto de estudo principal são as unidades lexicais e suas relações em contextos" (p.2). Para Biderman (2001) o léxico, não é apenas mental: tem um matiz social e cultural que diz o modo como categorizamos as coisas que nos rodeiam e que nos são (ou se nos fazem) significativas. Portanto, os autores ratificam a indissociabilidade entre língua e sociedade, em que uma reflete a outra e esse reflexo realiza-se, em grande parte, por meio do léxico empregado em uma comunidade. Desse modo, compreendendo léxico e semântica como campos indissociáveis em um estudo linguístico que contempla o perfil lexical de uma comunidade, apresentamos a seguir a análise das variantes para "pessoa tagarela"; "pessoa sovina"; "marido enganado"; "prostituta" e "bêbado", encontradas no léxico amapaense.

Ressalta-se que a análise dos dados será feita da seguinte forma: inicialmente, serão apresentados os dados nas cartas linguísticas extraídas do ALAP, que evidenciam os itens lexicais investigados nesse estudo; depois, serão descritas as variantes e, por 
fim, a análise em seu aspecto diatópico; porém, vale lembrar que essa análise considera apenas as variantes de maior frequência e que estão presentes na maior parte dos municípios pesquisados em todo o estado. Destaca-se ainda que a maioria das variantes encontradas coincide com aquelas mapeadas nas cartas do ALiB (CARDOSO et al., 2014).

A Figura 1, corresponde à carta lexical 43 do ALAP e ilustra os usos amapaenses para a designação "pessoa tagarela".

Figura 1 - carta linguística para o item lexical pessoa tagarela

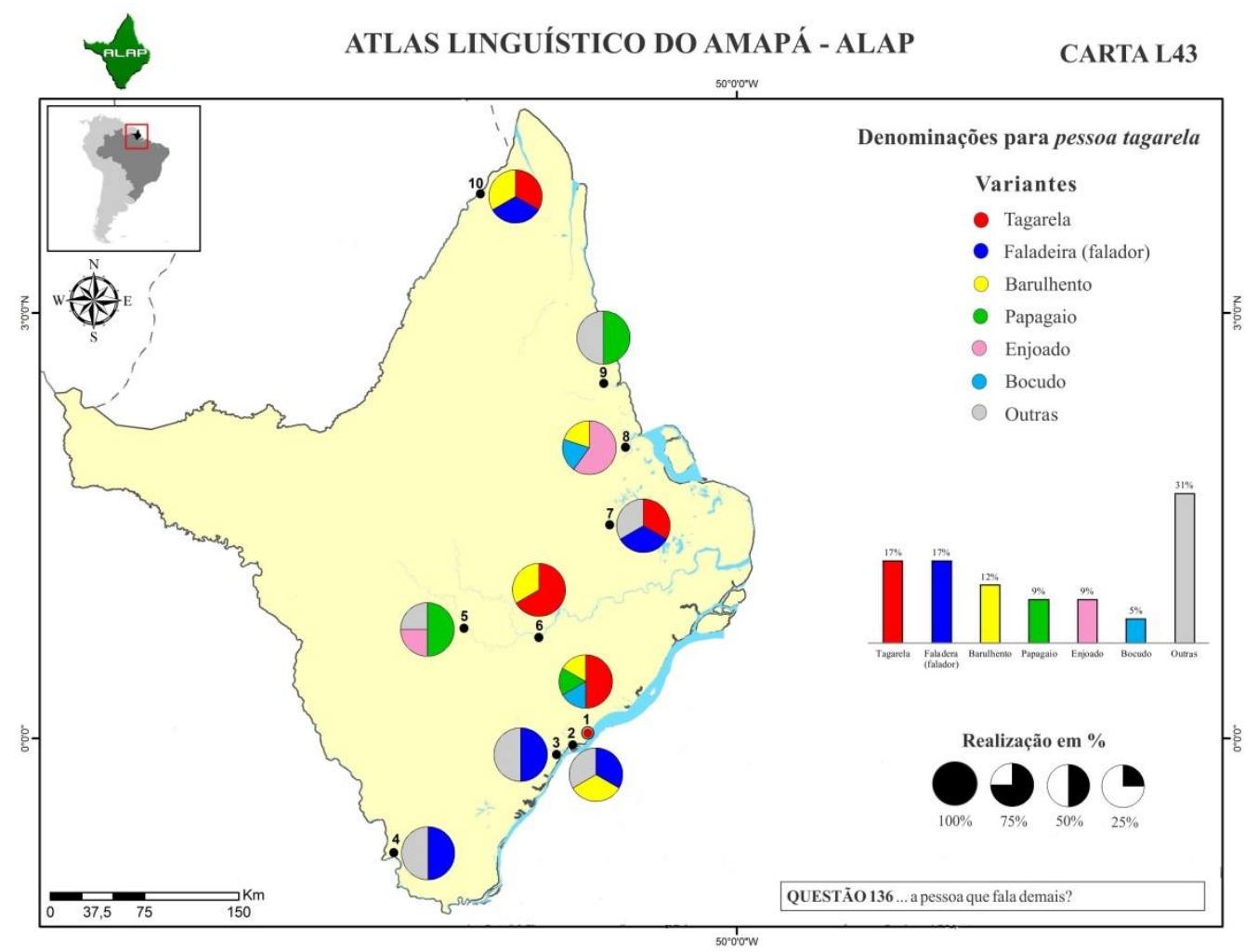

Fonte: ALAP, (Razky; Ribeiro; Sanches, 2017).

Como pode se observar, a lexia em questão apresenta-se bastante diversificada no Amapá registrando seis variantes, embora as mais frequentes sejam três: tagarela, faladeira e barulhento. Vale destacar que as variantes "tagarela" e "faladeira" apresentaram o mesmo percentual de realização: 17\%; seguidas de "barulhento" com $12 \%$ de frequência. Destacamos ainda que essas variantes com maior percentual de uso não são empregadas em todo o território amapaense, sendo mais comuns na porção centro-sul do estado. Por fim, convém dizer que houve um número significativo de 
outras respostas, cerca de $31 \%$, porém não foram mapeadas por realizarem-se de maneira muito particular em um ou outro falante e terem aparecido como últimas opções no vocabulário do falante, quando inquirido. Essas outras variantes aparecem no ALAP registradas em tabelas, no verso das cartas lexicais e são elas: língua solta, falante, fala muito, matraca, carretel, linguarudo, fofoqueiro e mexeriqueiro.

Aragão (2009) verifica as variantes mais recorrentes, empregadas nas capitais da Região Norte do Brasil, para "pessoa sovina", "marido enganado" e "prostituta", a partir dos dados do ALiB. Neste trabalho a autora registra para o item lexical "pessoa sovina" 9 variantes, porém apenas 1 coincide com os dados do ALAP, "mão de vaca". A Figura 2 retrata as ocorrências usadas na designação desse item.

Figura 2 - Carta linguística para o item lexical pessoa sovina

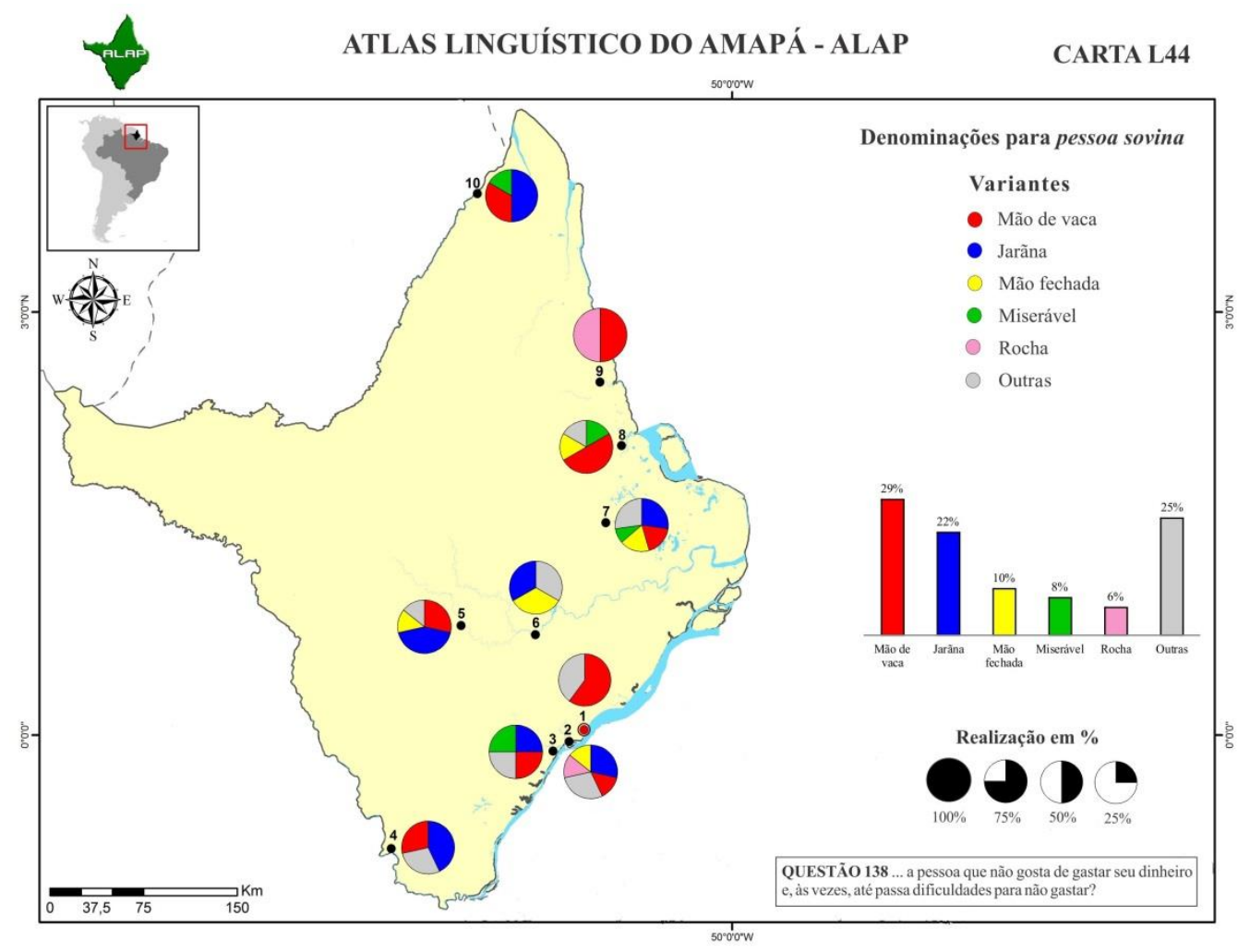

Fonte: ALAP (Razky; Ribeiro; Sanches, 2017).

Conforme a Figura 2 ocorrem cinco variantes de maior uso, mas "mão de vaca" e jarãna" são as mais recorrentes, com $29 \%$ e $22 \%$, respectivamente. A primeira ocorre em todo o estado, com exceção do ponto 6, Porto Grande; enquanto a segunda não se realizou em três localidades amapaenses. Destaque também para as outras ocorrências, 
que tal como na carta da Figura 1, teve realização significativa (25\%), mas pelas mesmas razões expostas na carta anterior, não foram mapeadas.

O item "marido enganado" no estudo de Aragão (2009) aponta 5 variantes (corno, chifrudo, traído, boi, marido enganado), que coincidem com as registradas no ALAP, com exceção para "abestado" que apareceu somente nos dados deste atlas. No entanto, consideramos este termo designativo de uma caracterização comportamental do indivíduo e não uma denominação relativa ao ser propriamente dito como as demais variantes traduzem. Além de que esse termo foi empregado somente em duas localidades do estado. A Figura 3 evidencia tais realizações.

Figura 3 - Carta linguística para o item lexical marido enganado

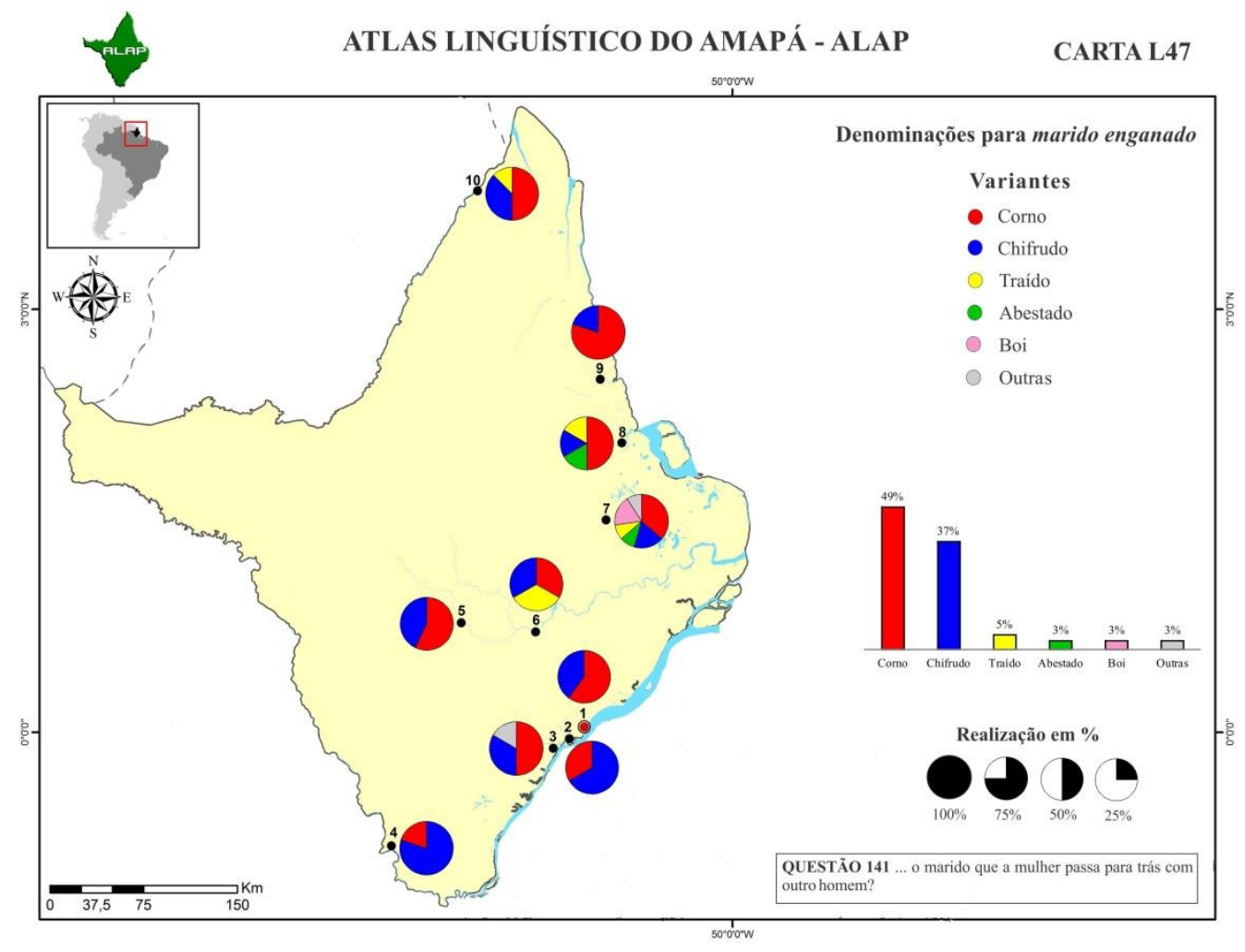

Fonte: ALAP (Razky; Ribeiro; Sanches, 2017)

A carta indica os termos mais empregados pelo falante amapaense, sendo "corno" e "chifrudo" as mais usadas, com 49\% e 37\%, respectivamente. Essas formas são encontradas em todos os pontos pesquisados no estado e, ressalta-se que o emprego de outras variantes ocorreu de forma muita reduzida, diferente do que se registrou nas cartas expostas nas Figuras 1 e 2, anteriormente.

Revista Moara, n. 54, ago-dez 2019 ISSN: 0104-0944

Recebido em 02/08/2019

Avaliado em 19/08/2019 
O outro item lexical analisado por Aragão (2009) corresponde a "prostituta", registrando um total de 10 variantes distribuídas entre as capitais das região norte do país. O ALAP aponta 06 variantes, as quais podem ser visualizadas na Figura 4 seguinte.

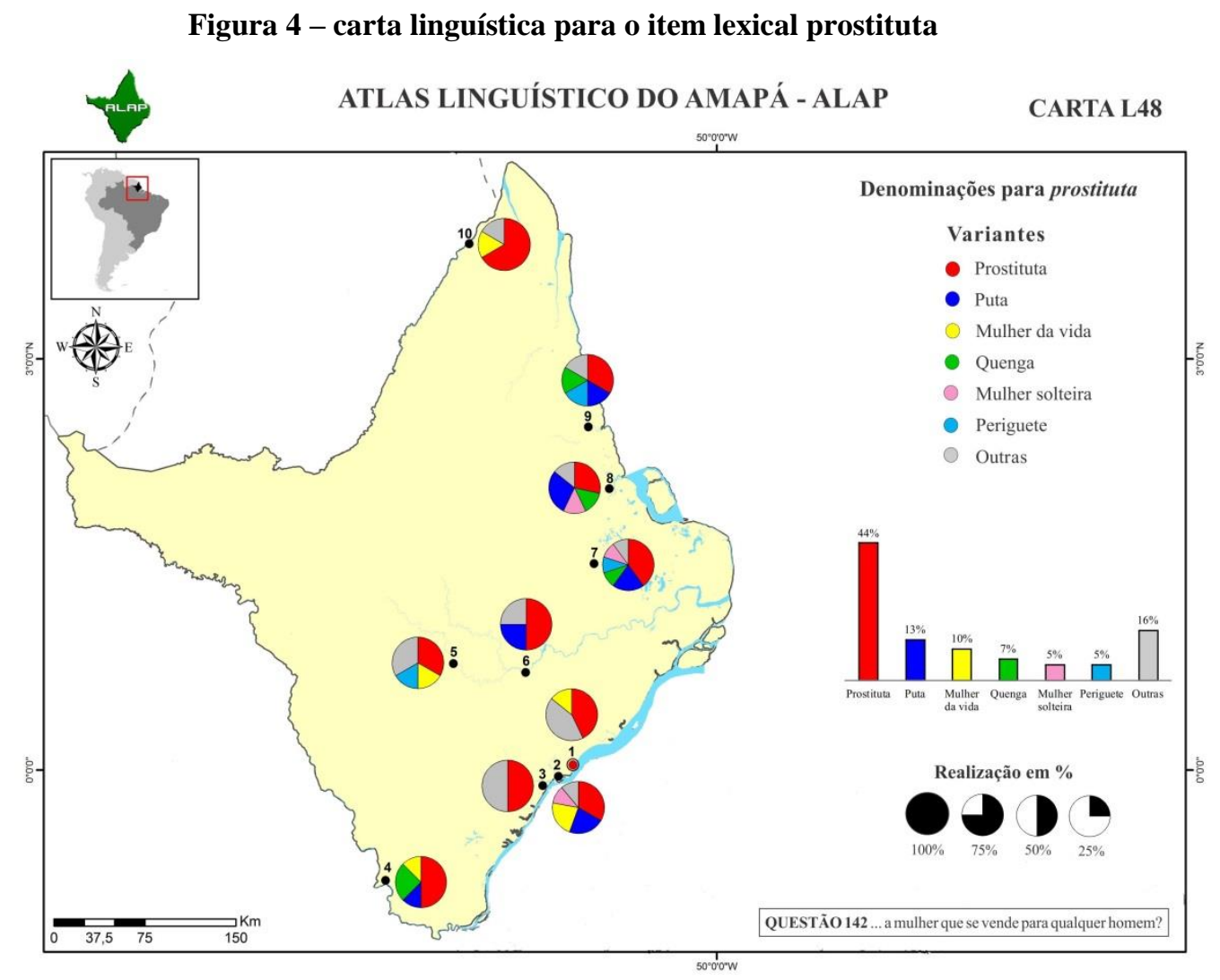

Fonte: ALAP (Razky; Ribeiro; Sanches, 2017).

Entre as 06 ocorrências para o referido item, a variante "prostituta" é a forma estatisticamente predominante, com $44 \%$ de frequência de uso; aparece em todo o estado, sendo que em algumas cidades ela divide o espaço com as demais variantes mapeadas, mas em outras ela se realiza de forma semi-categórica. Ao relacionarmos essas realizações ao estudo de Aragão (2009) verificamos que quatro são semelhantes: "prostituta', "puta", "mulher da vida", "quenga" e duas diferentes: "mulher solteira" e "periguete", ambas registradas apenas no ALAP. Essa situação ocorre em razão de o ALiB ter considerado apenas 2 pontos de inquérito: Oiapoque e a capital Macapá, ao 
passo que o ALAP considerou além dessas duas, outras localidades que foram justamente onde essas variantes ocorreram.

Por fim, o termo "bêbado" em que se registraram seis variantes mais produtivas, sendo "alcoólatra" a mais usada com frequência de 29\%. Essas realizações podem ser visualizadas na Figura 5.

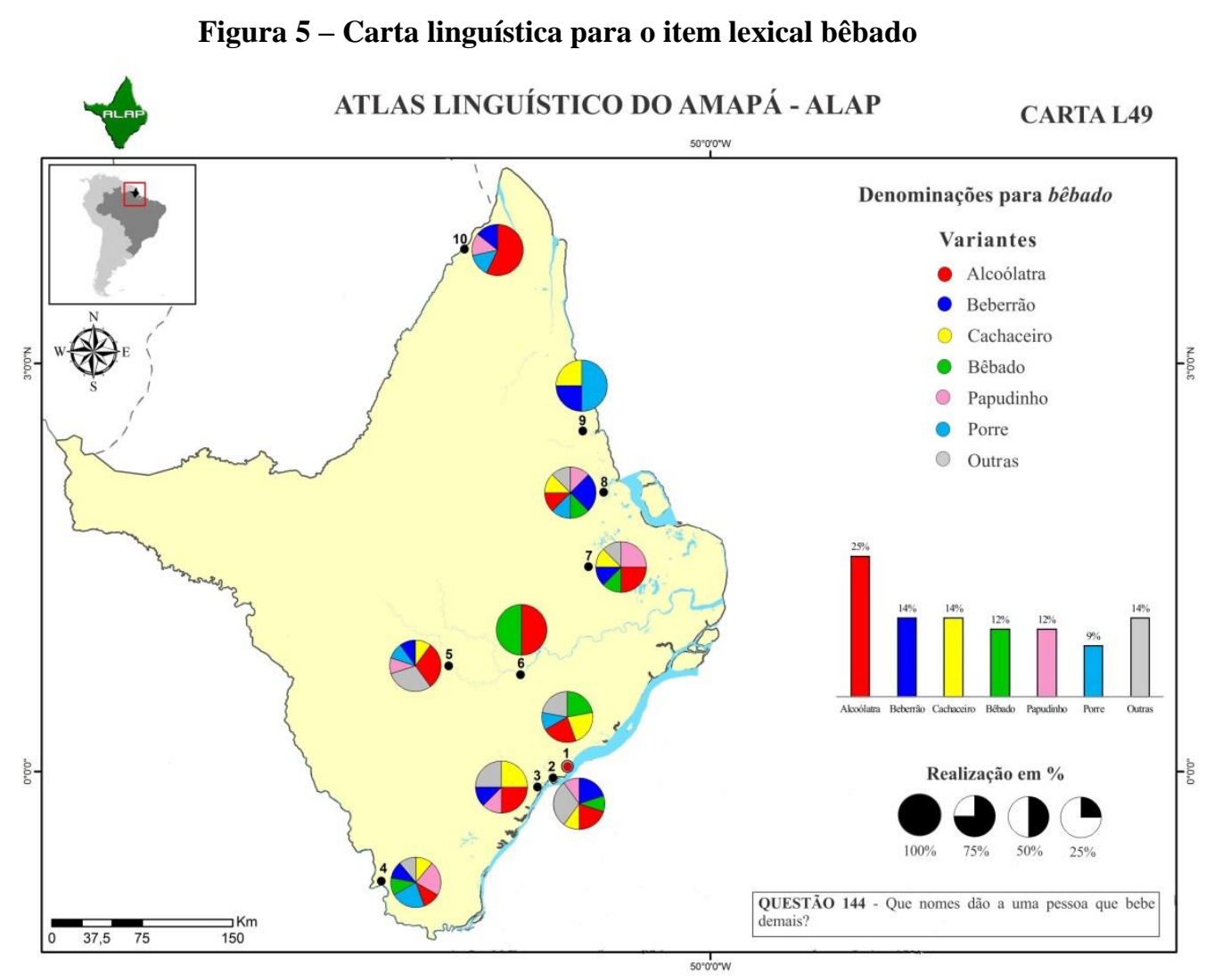

Fonte: ALAP (Razky; Ribeiro; Sanches, 2017).

A carta lexical 49 do ALAP, Figura 5, evidencia produtividade para o referido termo, o qual em apenas uma localidade, a de $n^{\circ} 6$, Porto Grande, mostrou somente duas variantes; o item mais frequente, alcoólatra, aparece em quase todos os pontos de inquérito, com exceção para o ponto 9, Calçoene. Destaque também para outras variantes que apresentaram um percentual de 14\%, porém não foram mapeadas por razões já explicitadas anteriormente. 


\section{Tecendo alguns comentários}

Os itens lexicais apresentados e mapeados nas cartas do ALAP refletem a diversidade lexical no estado do Amapá para as referidas designações. Esses itens não se distanciam muito do léxico nortista para alguns usos, conforme vimos em Aragão (2009). Merece destaque o termo "jarãna" que, entre as capitais do norte do Brasil, apareceu somente em Macapá, e no estado do Amapá foi a segunda variante mais usada, presente em $80 \%$ das localidades pesquisadas. O mesmo ocorreu para o item "prostituta" em que as variantes "mulher solteira" e "periguete" só foram registradas no ALAP. Entre essas variantes, vale informar que a primeira foi produzida somente pelos falantes da segunda faixa etária e a segunda apenas pelos mais jovens. Ambas ocorreram em três localidades do estado, conforme podemos observar na carta lexical 48 (Figura 4).

Merece destaque a denominação "mulher solteira" como resposta a pergunta feita para esse item: "como se chama a mulher que se vende para qualquer homem?" porém, compreende-se até certo ponto a referida designação, por ela ter sido empregada apenas por falantes da segunda faixa etária (acima de 60 anos) e moradores de municípios com características mais rurais; ou seja, há uma tendência na fala das pessoas mais velhas em refletir de forma muito forte ainda ideias, costumes e hábitos tradicionalistas e patriarcais.

Sobre essa questão, Brandão e Parente (2001) citam a perspectiva psico-social para justificar a linguagem dos idosos em muitos contextos, destacando que "as habilidades cognitivas são modeladas pelo contexto histórico e cultural", direcionando grande parte dos estudos sobre a linguagem do idoso "para a relação deste com a sociedade". É sabido que em tempos passados, o papel da mulher na sociedade voltavase exclusivamente para o casamento, ter filhos e cuidar do ambiente doméstico, refletindo, assim, a ideia de "mulher solteira" com um valor social negativo e pejorativo, bem diferente do que indica atualmente.

Um outro estudioso da linguagem dos idosos é Pretti (1991) que ao analisar as características do léxico no discurso do idoso, detectou o surgimento frequente de informações ligadas ao passado desses indivíduos, por meio do uso de sentenças, vocábulos, formas de tratamento e expressões antigas, evidenciando marcas lexicais de

Revista Moara, n. 54, ago-dez 2019 ISSN: 0104-0944

Recebido em 02/08/2019

Avaliado em 19/08/2019 
espaço e tempo, tal qual se observa no emprego da designação "mulher solteira" nos dados do ALAP.

Por outro lado, verificamos que os cinco itens lexicais discutidos nesse texto são comuns em quase toda a região norte do Brasil (CARDOSO et al., ALiB, 2014) configurando, simultaneamente, um panorama linguístico simétrico na região e diversidade local. Esse quadro reafirma a importância dos atlas linguísticos, sejam regionais ou nacionais na propagação e divulgação da língua usada pelos falantes de uma localidade, assim como permite conhecer de forma mais clara os reais usos linguísticos de uma comunidade, seja em sentido mais amplo, ou mais restrito.

\section{Considerações Finais}

A realização de pesquisas desta natureza ilustra e ratifica o papel dos atlas linguísticos estaduais, para um melhor conhecimento da língua portuguesa falada no país, assim como traduzem modos de definir e designar pessoas e situações contextuais do cotidiano na identificação de seus costumes e ideologias, os quais são comumente refletidos por meio de sua linguagem, fator de identificação regional, social e cultural.

Este estudo teve o propósito de apresentar o perfil lexical amapaense de determinados itens que integram o campo "convívio e comportamento social" do questionário semântico-lexical do ALiB (COMITÊ NACIONAL DO PROJETO ALiB, 2001), buscando não apenas descrever tais usos, mas também destacar os termos de uso mais local.

As cartas do ALAP permitem a visualização da forma como o fenômeno da variação linguística, em termos lexicais, ocorre no português falado no Amapá, ressaltando que por meio do registro dessa variação observamos o espaço de interação, onde as palavras desenvolvem valores significativos diversos e ampliam o panorama de configuração da linguagem, em que a diversidade lexical enriquece as situações de uso da língua vivenciadas pelo falante.

Revista Moara, n. 54, ago-dez 2019 ISSN: 0104-0944 


\section{REFERÊNCIAS}

ARAGÃO, M. S. S. O Léxico da Região Norte do Brasil. In: $61^{\mathrm{a}}$ Reunião Anual da SBPC, 2009, Manaus. Anais da $61^{\mathrm{a}}$ Reunião Anual da SBPC. Manaus: UFAM. Disponível em: http://www.sbpcnet.org.br/livro/61ra. Acesso em: 16/01/2018.

BIDERMAN, M. T. C. As Ciências do Léxico. In: OllVEIRA, A. M. P. P; ISQUERDO. A. N. (Orgs.). As ciências do léxico: lexicologia, lexicografia, terminologia. Campo Grande: Ed. UFMS. 2001. p. 153-166.

BRANDÃO, L.; PARENTE, M. A. M. P. Os Estudos de Linguagem do Idoso neste Último Século. Estudos Interdisciplinares, Porto Alegre, v. 3, p. 37-53, 2001. Disponível em: https://seer.ufrgs.br/RevEnvelhecer. Acesso em: 15/06/2019.

CARDOSO, S. A. M. A Geolinguística no Terceiro Milênio: monodimensional ou pluridimensional? Revista do GELNE, Salvador, v. 4, N. 2, 2002.

Editorial, 2010.

Geolinguística: tradição e modernidade. São Paulo: Parábola et al. Atlas Linguístico do Brasil: cartas linguísticas 1. v. 2. Londrina:

EDUEL, 2014.

Dialetologia. In: MOLLICA, M. C.; FERRAREZI JUNIOR, C.

(Orgs.). Sociolinguística, Sociolinguísticas: uma introdução. São Paulo: Contexto. 2016. p. 13-22.

COMITÊ NACIONAL DO PROJETO ALIB. Atlas Linguístico do Brasil. Questionários. Londrina: Eduel, 2001.

COSERIU, E. A geografia linguística. In: COSERIU, E. O homem e sua linguagem. Rio de Janeiro: Presença. 1982. p.79 - 116.

FERREIRA, C; CARDOSO, S.A. A Dialetologia no Brasil. São Paulo: Contexto, 1994.

POTTIER, Bernard. Théorie et Analyse en Linguistique. Paris: Hachette, 1987.

Revista Moara, n. 54, ago-dez 2019 ISSN: 0104-0944

Recebido em 02/08/2019

Avaliado em 19/08/2019 
PRETTI, D. A Linguagem dos Idosos: um estudo da análise da conversação. São Paulo: Contexto, 1991.

RAZKY, A.; RIBEIRO, C. M.R.; SANCHES, R. D. Atlas Linguístico do Amapá. São Paulo: Labrador, 2017.

ROSSI, N. Atlas Prévio dos Falares Baianos. Rio de Janeiro: Instituto Nacional do Livro, 1963.

THUN, H. A Dialetologia Pluridimensional no Rio da Prata. Porto Alegre: UFRGS, 1997.

O Velho e o Novo na Geolinguística. Trad. PAVAN, C. F. et al. Cadernos de Tradução, Porto Alegre, n.40, p.59-81, jan-jun2017. Disponível em: https://seer.ufrgs.br/cadernosdetraducao. Acesso em: 18/03/2019. 